\title{
Relation between cigarette smoking and ventilatory threshold in the Japanese
}

\author{
Nobuyuki Miyatake $\cdot$ Takeyuki Numata $\cdot$ Kenji Nishii $\cdot$ \\ Noriko Sakano • Takeshi Suzue • Tomohiro Hirao • \\ Motohiko Miyachi $\cdot$ Izumi Tabata
}

Received: 15 April 2010/Accepted: 12 August 2010/Published online: 9 September 2010

(C) The Japanese Society for Hygiene 2010

\begin{abstract}
The link between cigarette smoking and ventilatory threshold (VT) was investigated. We used data for 407 men and 418 women not taking medication. Habits of cigarette smoking were obtained through interviews by well-trained staff. The influence of cigarette smoking on oxygen uptake, work rate, and heart rate at VT was evaluated. Oxygen uptake at VT in women and work rate at VT in men with cigarette smoking were significantly lower than in subjects without cigarette smoking after adjusting for age. The differences of parameters at VT did not reach significant levels after adjusting for age and exercise habits in both sexes. However, in women without exercise habits, there was significant difference of oxygen uptake at VT between women with and without cigarette smoking after adjusting for age [cigarette smoking $(+): 11.5 \pm 1.8 \mathrm{ml} /$
\end{abstract}

N. Miyatake $(\bowtie) \cdot$ N. Sakano

Department of Hygiene, Faculty of Medicine,

Kagawa University, 1750-1, Miki, Kagawa 761-0793, Japan

e-mail: miyarin@med.kagawa-u.ac.jp

T. Numata

Okayama Southern Institute of Health,

Okayama Health Foundation, Okayama 700-0952, Japan

K. Nishii

Okayama Health Foundation Hospital,

Okayama Health Foundation, Okayama 700-0952, Japan

T. Suzue $\cdot$ T. Hirao

Department of Public Health, Faculty of Medicine,

Kagawa University, Kagawa 761-0793, Japan

M. Miyachi · I. Tabata

National Institute of Health and Nutrition,

Shinjuku, Tokyo 162-8636, Japan $\mathrm{kg} / \mathrm{min}$, cigarette smoking (-): $12.4 \pm 2.1 \mathrm{ml} / \mathrm{kg} / \mathrm{min}$, $p=0.0006]$. The number of cigarettes smoked per day and the Brinkman Index were not clearly correlated with oxygen uptake at VT. A combination of promoting exercise habits and prohibiting cigarette smoking might be recommended for improving the aerobic exercise level, especially in women.

Keywords Cigarette smoking - Ventilatory threshold . Oxygen uptake $\cdot$ Exercise habits

\section{Introduction}

Cigarette smoking has become an important public health challenge, and it has been reported that $39.4 \%$ of men and $11.0 \%$ of women are current smokers in Japan [1]. Cigarette smoking is also a strong risk factor for atherosclerosis and cardiovascular disease in a dose-dependent manner [2].

Exercise is considered as a useful method for preventing and improving atherosclerosis and cardiovascular disease. The ventilatory threshold (VT) is defined as the upper limit of aerobic exercise and is thought to serve as an accurate and reliable standard for exercise prescription [3]. Since the exercise intensity at VT is not harmful to cardiovascular function, it can be safely applied to patients with myocardial infarction as an exercise prescription [4]. We have previously reported that aerobic exercise level was significantly lower in subjects with metabolic syndrome than that in subjects without the syndrome [5], and the prevalence of metabolic syndrome was significantly higher in subjects with cigarette smoking than that in subjects without cigarette smoking [6]. However, the relationship between cigarette smoking and aerobic exercise level defined by VT is not fully discussed. 
The aim of this study is to explore the link between cigarette smoking and VT in the Japanese population.

\section{Subjects and methods}

\section{Subjects}

We used data for 407 Japanese men (aged $42.1 \pm 11.4$ years) and 418 women (aged $44.8 \pm 12.0$ years) (5.8\%), retrospectively from a database of 14,345 subjects who met the following criteria: they had (1) wanted to change their lifestyle, i.e., diet and exercise habits, and had received an annual health checkup from June 1997 to May 2007 at Okayama Southern Institute of Health, (2) they had received anthropometric and oxygen uptake at VT measurements and evaluation of cigarette smoking as part of the annual health checkup, (3) received no medications for diabetes, hypertension, and/or dyslipidemia, and (4) provided written informed consent (Table 1).

Ethical approval for the study was obtained from the Ethical Committee of Okayama Health Foundation.

\section{Anthropometric measurements}

Anthropometric and body compositions were evaluated based on the following parameters: height, body weight, abdominal circumference, and hip circumference. Abdominal circumference was measured at the umbilical level, and the hip was measured at the widest circumference over the trochanter in standing subjects after normal exhalation [7].

\section{Cigarette smoking}

The data on cigarette smoking were obtained at interviews by well-trained staff in a structured way. The subjects were asked

Table 1 Clinical profiles of enrolled subjects

\begin{tabular}{lcc}
\hline & \multicolumn{2}{c}{ Mean \pm SD } \\
\cline { 2 - 3 } & Men & Women \\
\hline Number of subjects & 407 & 418 \\
Age (years) & $42.1 \pm 11.4$ & $44.8 \pm 12.0$ \\
Height $(\mathrm{cm})$ & $169.9 \pm 5.8$ & $156.0 \pm 5.5$ \\
Body weight (kg) & $79.1 \pm 13.3$ & $65.0 \pm 12.9$ \\
Abdominal circumference (cm) & $91.1 \pm 10.9$ & $81.4 \pm 11.2$ \\
Hip circumference (cm) & $98.6 \pm 6.8$ & $96.7 \pm 8.5$ \\
$\begin{array}{l}\text { Oxygen uptake at ventilatory threshold } \\
\text { (ml/kg/min) }\end{array}$ & $14.9 \pm 3.9$ & $12.6 \pm 2.5$ \\
$\begin{array}{l}\text { Work rate at ventilatory threshold (W) } \\
\text { Heart rate at ventilatory threshold } \\
\text { (beats/min) }\end{array}$ & $82.9 \pm 24.4$ & $51.3 \pm 14.6$ \\
\hline
\end{tabular}

if they currently smoked cigarettes. When the answer was "yes," they were classified as current smokers and further questions were asked regarding the average number of cigarettes smoked per day and their age at starting smoking. When the answer was "no," they were classified as nonsmokers.

Based on answers to those questions, the cumulative amount of cigarette consumption expressed as the Brinkman Index (BI: number of cigarettes consumed per day multiplied by years of smoking) [8].

\section{Exercise testing}

A graded ergometer exercise protocol [9] was performed. Two hours after breakfast, a resting electrocardiogram (ECG) was recorded and blood pressure was measured. Then, all participants were given graded exercise after 3 min of pedaling on a bicycle ergometer at zero load (Excalibur V2.0; Lode BV, Groningen, The Netherlands). The profile of incremental workloads was automatically defined using the methods of Jones et al. [9], in which the workloads reach the predicted $\dot{V} \mathrm{O}_{2 \max }$ in $10 \mathrm{~min}$. A pedaling cycle rate of $60 \mathrm{rpm}$ was maintained. Loading was terminated when the appearance of symptoms forced the subject to stop. During the test, ECG was monitored continuously together with recording of heart rate (HR). Exhaled gas was collected, and rates of oxygen consumption $\dot{V} \mathrm{O}_{2}$ and carbon dioxide production $\left(\dot{V} \mathrm{CO}_{2}\right)$ were measured breath by breath using a cardiopulmonary gas exchange system (Oxycon Alpha; Mijnhrdt b.v., The Netherlands). VT was determined by the standard of Wasserman et al. [3], Davis et al. [10], and the V-slope method of Beaver [11] from $\dot{V} \mathrm{O}_{2}, \dot{V} \mathrm{CO}_{2}$, and minute ventilation $(\dot{V} \mathrm{E})$. At $\mathrm{VT}, \dot{V} \mathrm{CO}_{2}(\mathrm{ml} / \mathrm{kg} / \mathrm{min})$, work rate $(\mathrm{W})$, and heart rate (beats/min) were measured and recorded.

\section{Exercise habits}

The data on exercise habits were obtained through interviews by well-trained staff in a structured way according to the National Nutrition Survey in Japan [12]. The subjects were asked if they currently exercise (over the level of 30 min per session, two times per week, and prolonged duration for 3 months). When the answer was "yes," they were classified as subjects with exercise habits. When the answer was "no," they were classified as subjects without exercise habits.

Statistical analysis

All data are expressed as mean \pm standard deviation (SD). Statistical analysis was performed using an unpaired $t$ test, $\chi^{2}$ test, logistic regression analysis, covariance analysis, 
one-way analysis of variance (ANOVA), and Scheffe's $F$ test, where $p<0.05$ was considered to be statistically significant. We used the unpaired $t$ test to compare parameters between subjects with and without cigarette smoking; the $\chi^{2}$ test was used to evaluate the relationship between cigarette smoking and exercise habits. Logistic regression analysis and covariance analysis were also used to adjust for parameters. ANOVA and Scheffe's $F$ test were used to compare among subjects with and without cigarette smoking and exercise habits. Pearson's correlation coefficients were calculated and used to test the significance of the linear relationship between oxygen uptake at VT and the number of cigarette smoked per day, the BI.

\section{Results}

The results of age and parameters at VT in subjects with and without cigarette smoking are presented in Table 2. A total of 166 men (40.8\%) and 46 women (11.0\%) were current smokers. In men, there was no significant difference of age between subjects with and without cigarette smoking. Oxygen uptake and work rate at VT in subjects with cigarette smoking were significantly lower than those in subjects without cigarette smoking. However, in women, age in subjects with cigarette smoking was significantly lower than that in subjects without cigarette smoking. Therefore, to avoid the influence of age on parameters at VT, we used age as a covariate and compared parameters at VT using covariance analysis. Oxygen uptake in women and work rate at VT in men with cigarette smoking were significantly lower than in subjects without cigarette smoking even after adjusting for age (Table 2).

It is well known that aerobic exercise level is closely linked to exercise habits [5]. We evaluated the relationship between cigarette smoking and exercise habits (Table 3). A total of 164 men $(40.3 \%)$ and 105 women $(25.1 \%)$ were defined as having exercise habits. In men, the prevalence of subjects with cigarette smoking was significantly lower in subjects with exercise habits than that in subjects without exercise habits (Table 3). However, no significant difference in the prevalence of cigarette smoking in subjects with and without exercise habits was noted in women.

To avoid the influence of age and exercise habits on cigarette smoking, we used age, exercise habits, and parameters of VT as explanatory variables, and cigarette smoking as a response variable. No significant differences of parameters at VT in subjects with and without cigarette

Table 2 Comparison of parameters at ventilatory threshold between subjects with and without cigarette smoking

\begin{tabular}{|c|c|c|c|c|c|c|c|}
\hline & & \multicolumn{3}{|c|}{ Mean \pm SD } & \multirow[t]{2}{*}{$p$} & \multirow{2}{*}{$\begin{array}{l}p \text { (after } \\
\text { adjusting } \\
\text { for age) }\end{array}$} & \multirow{2}{*}{$\begin{array}{l}p \text { (after adjusting } \\
\text { for age } \\
\text { and exercise habits) }\end{array}$} \\
\hline & & \multicolumn{2}{|c|}{$\begin{array}{l}\text { Cigarette } \\
\text { smoking }(+)\end{array}$} & $\begin{array}{l}\text { Cigarette } \\
\text { smoking (-) }\end{array}$ & & & \\
\hline \multicolumn{8}{|l|}{ Men } \\
\hline \multicolumn{2}{|l|}{ Number of subjects } & \multicolumn{2}{|c|}{166} & 241 & & & \\
\hline \multicolumn{2}{|l|}{ Age (years) } & \multicolumn{2}{|c|}{$41.8 \pm 11.0$} & $42.4 \pm 11.7$ & 0.5803 & & \\
\hline \multicolumn{2}{|c|}{ Oxygen uptake at ventilatory threshold $(\mathrm{ml} / \mathrm{kg} / \mathrm{min})$} & \multicolumn{2}{|c|}{$14.3 \pm 3.1$} & $15.3 \pm 4.4$ & 0.0193 & 0.0595 & 0.1156 \\
\hline \multicolumn{2}{|c|}{ Work rate at ventilatory threshold (W) } & \multicolumn{2}{|c|}{$79.8 \pm 20.7$} & $85.0 \pm 26.5$ & $\mathbf{0 . 0 3 3 3}$ & $\mathbf{0 . 0 3 7 7}$ & 0.0764 \\
\hline \multicolumn{2}{|c|}{ Heart rate at ventilatory threshold (beats/min) } & \multicolumn{2}{|c|}{$105.5 \pm 11.0$} & $106.3 \pm 12.5$ & 0.4683 & 0.9970 & 0.1839 \\
\hline \multicolumn{8}{|l|}{ Women } \\
\hline \multicolumn{2}{|l|}{ Number of subjects } & \multicolumn{2}{|c|}{46} & 372 & & & \\
\hline \multicolumn{2}{|l|}{ Age (years) } & \multicolumn{2}{|c|}{$39.6 \pm 12.9$} & $45.4 \pm 11.8$ & 0.0019 & & \\
\hline \multicolumn{2}{|c|}{ Oxygen uptake at ventilatory threshold $(\mathrm{ml} / \mathrm{kg} / \mathrm{min})$} & \multicolumn{2}{|c|}{$12.0 \pm 2.8$} & $12.7 \pm 2.4$ & 0.1011 & 0.0120 & 0.0514 \\
\hline \multicolumn{2}{|c|}{ Work rate at ventilatory threshold (W) } & \multicolumn{2}{|c|}{$52.9 \pm 18.1$} & $51.1 \pm 14.1$ & 0.4092 & 0.6883 & 0.6414 \\
\hline Heart rate at ventilatory thresho & (beats/min) & 106 & & $107.1 \pm 11.9$ & 0.6136 & 0.2680 & 0.0881 \\
\hline $\begin{array}{l}\text { Table } 3 \text { Relationship between } \\
\text { cigarette smoking and exercise } \\
\text { habits }\end{array}$ & & & $\begin{array}{l}\text { Exe } \\
\text { habi }\end{array}$ & $\begin{array}{l}\text { se } \\
(+)\end{array}$ & $\begin{array}{l}\text { cise } \\
\text { s }(-)\end{array}$ & $p$ & $\begin{array}{l}p \text { (after adjusting } \\
\text { for age) }\end{array}$ \\
\hline & Men & & & & & & \\
\hline & Cigarette smoki & $(+)$ & 52 & 11 & & 0.0022 & 0.0024 \\
\hline & Cigarette smoki & $(-)$ & 112 & 12 & & & \\
\hline & Women & & & & & & \\
\hline & Cigarette smoki & $(+)$ & 8 & & & 0.2002 & 0.5304 \\
\hline & Cigarette smoki & $(-)$ & 97 & 27 & & & \\
\hline
\end{tabular}


smoking were noted after adjusting for age and exercise habits in both sexes (Table 2). We separately compared oxygen uptake at VT in subjects without exercise habits. After adjusting for age, no significant difference of oxygen uptake at VT was noted between men with and without cigarette smoking [cigarette smoking $(+): 13.8 \pm 2.6 \mathrm{ml} /$ $\mathrm{kg} / \mathrm{min}$, cigarette smoking (-): $13.8 \pm 2.5 \mathrm{ml} / \mathrm{kg} / \mathrm{min}$, $p=0.4089$ ]. However, there was significant difference of oxygen uptake at VT between women with and without cigarette smoking [cigarette smoking $(+): 11.5 \pm 1.8 \mathrm{ml} /$ $\mathrm{kg} / \mathrm{min}$, cigarette smoking $(-): 12.4 \pm 2.1 \mathrm{ml} / \mathrm{kg} / \mathrm{min}$, $p=0.0006]$.

In addition, we compared the parameters of VT among subjects with and without cigarette smoking and exercise habits [A: cigarette smoking $(+)$ exercise habits $(+), \mathrm{B}$ : cigarette smoking $(-)$ exercise habits $(+), \mathrm{C}$ : cigarette smoking (+) exercise habits (-), D: cigarette smoking (-) exercise habits (-)] (Table 4). In men, oxygen uptake at VT in group $C$ and D was significantly lower than that in group $\mathrm{A}$ and $\mathrm{B}$. Work rate at $\mathrm{VT}$ in group $\mathrm{C}$ and $\mathrm{D}$ was significantly lower than that in group B. No significant differences of heart rate were not noted among the four groups. In women, oxygen uptake at VT in group $\mathrm{C}$ was significantly lower than that in group A and $\mathrm{B}$. Work rate at VT in group A was significantly higher than that in group B, C, and D. Heart rate at VT in group D was significantly higher than that in group B. Oxygen uptake at VT in group A and B (with exercise habits) was higher than that in group $\mathrm{C}$ and $\mathrm{D}$ (without exercise habits) in both sexes, as in our previous report [5].

Finally, we evaluated the relationship between the number of cigarettes smoked per day and oxygen uptake at $\mathrm{VT}$, and also between the BI and oxygen uptake at VT (Fig. 1). The number of cigarettes smoked per day was not correlated with oxygen uptake at VT in either sex (men $r=-0.172, p=0.0265$; women $r=-0.294, p=$ $0.0470)$. BI was also not clearly correlated with oxygen uptake at VT (men $r=-0.192, p=0.0132$; women $r=-0.214, p=0.1535)$. In subjects without exercise habits, the number of cigarettes smoked per day was not correlated with oxygen uptake at VT in either sex (men $r=-0.072, p=0.4487$; women $r=-0.180, p=0.2791$ ). BI was also not clearly correlated with oxygen uptake at VT (men $r=-0.135, p=0.1515$; women $r=-0.088$, $p=0.5976)$.

\section{Discussion}

Impairment of pulmonary oxygen exchange [13, 14], downregulation of adrenergic receptors [15], and long-term cardiac damage caused by stimulation of catecholamine by smoking [16] may also in part explain lower oxygen uptake at VT in subjects with cigarette smoking. Some crosssectional studies show that cigarette smoking is correlated with cardiovascular fitness [17-19]. Hirsch et al. [17] evaluated the immediate effects of cigarette smoking on aerobic exercise capacity, and cigarette smoking resulted in a significantly lower $\dot{V} \mathrm{O}_{2 \max }$ and higher heart rate after 3 cigarettes/h for $5 \mathrm{~h}$. Marti et al. [18] reported that, among army conscripts, the distance covered in a 12-min endurance run was inversely related to daily cigarette consumption and years of smoking. Rotstein et al. [19] also reported that smoking retards physiological responses to submaximal exercise immediately after smoking three cigarettes. In a longitudinal analysis, Sandvik et al. [20] showed that decline in physical fitness and lung function was greater among smokers than that among nonsmokers

Table 4 Comparison of parameters at ventilatory threshold among subjects with and without cigarette smoking and exercise habits

\begin{tabular}{|c|c|c|c|c|}
\hline & $\begin{array}{l}\text { A } \\
\text { Cigarette smoking }(+) \\
\text { Exercise habits }(+)\end{array}$ & $\begin{array}{l}\text { B } \\
\text { Cigarette smoking (-) } \\
\text { Exercise habits }(+)\end{array}$ & $\begin{array}{l}\text { C } \\
\text { Cigarette smoking }(+) \\
\text { Exercise habits }(-)\end{array}$ & $\begin{array}{l}\text { D } \\
\text { Cigarette smoking (-) } \\
\text { Exercise habits (-) }\end{array}$ \\
\hline \multicolumn{5}{|l|}{ Men } \\
\hline Number of subjects & 52 & 112 & 114 & 129 \\
\hline Oxygen uptake at ventilatory threshold $(\mathrm{ml} / \mathrm{kg} / \mathrm{min})$ & $15.6 \pm 3.7$ & $16.9 \pm 5.4$ & $13.8 \pm 2.6^{\mathrm{ab}}$ & $13.8 \pm 2.5^{\mathrm{ab}}$ \\
\hline Work rate at ventilatory threshold (W) & $84.8 \pm 25.2$ & $92.5 \pm 31.8$ & $77.5 \pm 18.0^{\mathrm{b}}$ & $78.6 \pm 18.8^{\mathrm{b}}$ \\
\hline Heart rate at ventilatory threshold (beats/min) & $103.8 \pm 12.2$ & $104.7 \pm 13.3$ & $106.2 \pm 10.3$ & $107.7 \pm 11.6$ \\
\hline \multicolumn{5}{|l|}{ Women } \\
\hline Number of subjects & 8 & 97 & 38 & 275 \\
\hline Oxygen uptake at ventilatory threshold $(\mathrm{ml} / \mathrm{kg} / \mathrm{min})$ & $14.4 \pm 5.0$ & $13.2 \pm 3.3$ & $11.5 \pm 1.8^{\mathrm{ab}}$ & $12.4 \pm 2.1$ \\
\hline Work rate at ventilatory threshold (W) & $70.0 \pm 27.0$ & $53.2 \pm 17.3^{\mathrm{a}}$ & $49.3 \pm 13.5^{\mathrm{a}}$ & $50.3 \pm 12.8^{\mathrm{a}}$ \\
\hline Heart rate at ventilatory threshold (beats/min) & $105.6 \pm 13.3$ & $104.1 \pm 12.0$ & $106.3 \pm 11.2$ & $108.2 \pm 11.7^{\mathrm{b}}$ \\
\hline
\end{tabular}

Mean \pm SD

${ }^{\mathrm{a}} p<0.05$ versus cigarette smoking $(+)$, exercise habits $(+)$

${ }^{\mathrm{b}} p<0.05$ versus cigarette smoking $(-)$, exercise habits $(+)$ 
Fig. 1 Simple correlation analysis between the number of cigarettes smoked per day and oxygen uptake at ventilatory threshold (a men, b women), and between the Brinkman Index and oxygen uptake at ventilatory threshold (c men, d women)
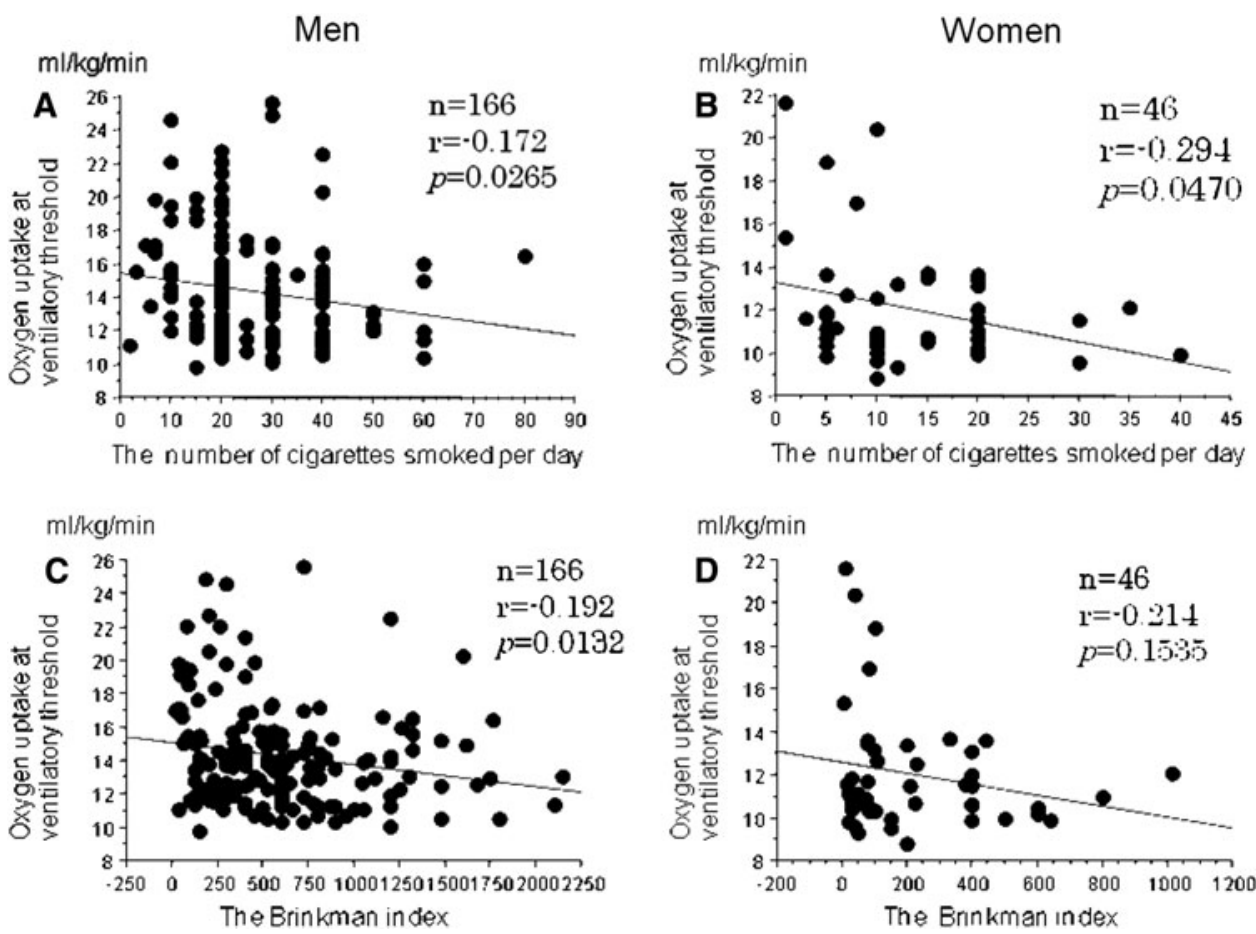

among 1,393 men over 7 years. In this study, we solely evaluated the relationship between cigarette smoking and aerobic exercise level defined by VT in the Japanese. Exercise habits were closely linked to cigarette smoking in men, and the differences of parameters at VT between subjects with and without cigarette smoking were attenuated after adjusting for age and exercise habits. However, in women without exercise habits, oxygen uptake at VT in women with cigarette smoking was significantly lower than that in women without, after adjusting for age. In addition, we compared oxygen uptake at VT among subjects with and without cigarette smoking and exercise habits, and found that oxygen uptake at VT in group B was highest among four groups in men. Oxygen uptake at VT in group $\mathrm{C}$ was lowest among four groups in both sexes. Taken together, a combination of promoting exercise habits and prohibiting cigarette smoking might be considered for improving aerobic exercise level, especially in women.

Potential limitations still remain in this study. First, our study was a cross-sectional and not a longitudinal study. Second, 407 men and 418 women in our study voluntarily underwent measurements; they were therefore more likely to be health conscious compared with the average person. Third, we could not show a clear relation between cigarette smoking and oxygen uptake at VT. Fourth, the relationship between cigarette smoking and exercise habits was not noted in women. The low prevalence of subjects with exercise habits and cigarette smoking might affect the results. However, it seems reasonable to suggest that prohibiting smoking and promoting exercise habits might result in amelioration of aerobic exercise level in some Japanese. Sandvik et al. [21] reported that physical fitness was a graded, independent, long-term predictor of mortality from cardiovascular causes in healthy, middle-aged men. To show this, further prospective studies are needed in the Japanese.

Acknowledgments This research was supported in part by Research Grants from the Ministry of Health, Labor, and Welfare, Japan.

\section{References}

1. The National Nutrition Survey in Japan. http://www.mhlw. go.jp/houdou/2008/12/d1/h1225-5j.pdf. Accessed 3 April 2010 (in Japanese).

2. Peto R. Smoking and death: the past 40 years and the next 40 . BMJ. 1994;209:937-9.

3. Wasserman K, Whipp BJ, Koyl SN, Beaver WL. Anaerobic threshold and respiratory gas exchange during exercise. J Appl Physiol. 1973;35:236-43.

4. Weber KT, Janicki JS. Cardiopulmonary exercise testing for evaluation of chronic cardiac failure. Am J Cardiol. 1985;55: 22A-31A.

5. Miyatake N, Saito T, Wada J, Miyachi M, Tabata I, Matsumoto $\mathrm{S}$, et al. Comparison of ventilatory threshold and exercise habits between Japanese men with and without metabolic syndrome. Diabetes Res Clin Prac. 2007;77:314-9.

6. Miyatake N, Wada J, Kawasaki Y, Nishii K, Makino H, Numata T. Relationship between metabolic syndrome and cigarette smoking in the Japanese population. Intern Med. 2006;45:1039-43.

7. Committee to evaluate diagnostic standards for metabolic syndrome. Definition and the diagnostic standard for metabolic syndrome. Nippon Naika Gakkai Zasshi 2005;94:794-809 (in Japanese). 
8. Brinkman GL, Coates EO Jr. The effect of bronchitis, smoking and occupation on ventilation. Ann Rev Respir Dis. 1963;87: 684-93.

9. Jones NL, Makrides L, Hitchcock C, Chypchar T, McCartney N. Normal standards for an incremental progressive cycle ergometer test. Am Rev Respir Dis. 1985;131:700-8.

10. Davis JA, Frank MH, Whipp BJ, Wasserman K. Anaerobic threshold alterations caused by endurance training in middle-aged men. J Appl Physiol. 1979;46:1039-46.

11. Beaver WL, Wasserman K, Whipp BJ. A new method for detecting anaerobic threshold by gas exchange. J Appl Physiol. 1986;60:2020-7.

12. The National Nutrition Survey in Japan. http://www.mhlw.go.jp/ houdou/2008/12/dl/h1225-5i.pdf (in Japanese), Accessed 5 April 2010.

13. Green MS, Jucha E, Luz Y. Blood pressure in smokers and nonsmokers: epidemiologic findings. Am Heart J. 1986;111:93240.

14. Powers SK, Lawler J, Dempsey JA, Dodd S, Landry G. Effects of incomplete pulmonary gas exchange on $V \mathrm{O}_{2 \max }$. J Appl Physiol. 1989;66:2491-5.

15. Laustiola KE, Lassila R, Kaprio J, Koskenvuo M. Decreased $\beta$-adrenergic receptor density and catecholamine response in male cigarette smokers. A study of monozygotic twin pairs discordant for smoking. Circulation. 1988;78:1234-40.

16. Cryer PE, Haymond MW, Santiago JV, Shah SD. Norepinephrine and epinephrine release and adrenergic mediation of smokingassociated hemodynamic and metabolic events. N Engl J Med. 1976;295:573-7.

17. Hirsch GL, Sue DY, Wasserman K, Robinson TE, Hansen JE. Immediate effects of cigarette smoking on cardiorespiratory responses to exercise. J Appl Physiol. 1985;58:1975-81.

18. Marti B, Abelin T, Minder CE. Vader JP: Smoking, alcohol consumption, and endurance capacity: an analysis of 6500 19-year-old conscripts and 4,100 joggers. Prev Med. 1988;17: 79-92.

19. Rotstein A, Sagiv M, Yaniv-Tamir A, Fisher N, Dotan R. Smoking effect on exercise response kinetics of oxygen uptake and related variables. Int J Sports Med. 1991;12:281-4.

20. Sandvik L, Erikssen G, Thaulow E. Long term effects of smoking on physical fitness and lung function: a longitudinal study of 1393 middle aged Norwegian men for seven years. BMJ. 1995;311: 715-8.

21. Sandvik L, Erikssen J, Thaulow E, Erikssen G, Mundal R, Rodahl K. Physical fitness as a predictor of mortality among healthy, middle-aged Norwegian men. N Engl J Med. 1993;25:533-7. 